\title{
OPEN Prevalence of peripheral neuropathy defined by monofilament insensitivity in middle-aged and older adults in two US cohorts
}

\begin{abstract}
Caitlin W. Hicks ${ }^{1}$, Dan Wang ${ }^{2}$, B. Gwen Windham ${ }^{3}$, Kunihiro Matsushita ${ }^{2}$ \& Elizabeth Selvin ${ }^{2}$
Peripheral neuropathy is associated with substantial morbidity, but risk factors other than diabetes are largely uncharacterized. The aim of this study was to describe the prevalence and risk factors for peripheral neuropathy in adults with and without diabetes from two different population-based studies in the US. We performed a cross-sectional analysis of 5200 black and white participants from NHANES (1999-2004, age 40-85 years) and 3362 black and white participants from the ARIC Study (2016-2017, age 70-89 years) who underwent monofilament testing for peripheral neuropathy using a shared protocol. We used logistic regression to quantify age, sex, and race-adjusted risk factor associations for peripheral neuropathy among middle-aged ( $40-69$ years) and older ( $\geq 70$ years) adults. The age, sex, and race-adjusted prevalence of peripheral neuropathy (decreased sensation on monofilament testing) was $10.4 \%$ for middle-aged adults in NHANES, $26.8 \%$ for older adults in NHANES, and $39.2 \%$ for older adults in ARIC. Diabetes was an important risk factor, but more strongly associated with peripheral neuropathy in middle-aged (OR $\sim$ for long-standing diabetes) compared to older adults (ORs 1.5-2). Male sex (ORs 2), black race (ORs 1.3-1.5), and greater height (ORs 1.53 ) were robust risk factors for peripheral neuropathy. Other risk factors included body mass index, education, and peripheral artery disease. The burden of peripheral neuropathy defined by abnormal monofilament testing among older adults is substantial, even among adults without diabetes. Studies are needed to understand the etiology and prognosis of peripheral neuropathy in the absence of diabetes.
\end{abstract}

Peripheral neuropathy $(\mathrm{PN})$ resulting in decreased lower extremity sensation is a common sequela of diabetes ${ }^{1-5}$. The consequences of PN can be devastating, including foot ulcers, major amputation, falls, intracranial injuries, and impaired quality of life ${ }^{6-8}$. We have recently shown that $\mathrm{PN}$ is independently associated with mortality in the general population, including among adults both with and without diabetes 9 . Despite substantial associated morbidity, the epidemiology and risk factors associated with PN in older adults are relatively uncharacterized, especially in adults without a history of diagnosed diabetes. There have been a number of prior cohort studies describing the epidemiology and risk factors associated with $\mathrm{PN}^{10-17}$. However, previous studies have typically focused on middle-aged adults or persons with diabetes.

Monofilament testing is an inexpensive, easy-to-use test to screen for PN. According to the American Diabetes Association, the 10-g monofilament test is the gold standard test to diagnose decreased lower extremity sensation resulting from $\mathrm{PN}^{18}$. Prospective studies have shown that decreased sensation to monofilament testing is highly predictive of foot ulceration ${ }^{19,20}$, and thus is an essential component of diabetic foot exams ${ }^{21}$. Age is a risk factor for PN, but age-related increases in the prevalence of PN in persons without diabetes and risk factors for PN in older adults have not been a focus in prior studies.

${ }^{1}$ Division of Vascular Surgery and Endovascular Therapy, Johns Hopkins University School of Medicine, Baltimore, MD, USA. '2Department of Epidemiology, Johns Hopkins Bloomberg School of Public Health, 2024 E. Monument St., Suite 2-600, Baltimore, MD 21287, USA. ${ }^{3}$ Department of Medicine, University of Mississippi Medical Center, Jackson, MS, USA. ${ }^{\square}$ email: eselvin@jhu.edu 
One of the only large US population-based studies to implement standardized monofilament testing was the 1999-2004 National Health and Nutrition Examination Survey (NHANES) ${ }^{16,17}$. The Atherosclerosis Risk in Communities Study (ARIC) is a community-based study that has collected longitudinal medical, social, and demographic data from more than 15,000 participants over the past 30 years. Between 2016 and 2017 (ARIC visit 6), all ARIC participants underwent standardized monofilament testing for PN. In contrast to NHANES, which enrolled participants $\geq 40$ years of age, ARIC participants were $\geq 70$ years of age at the time of monofilament testing. As a result, ARIC offers a unique opportunity to study the prevalence and risk factors associated with PN in a sample of older adults. The aim of this study was to describe the prevalence of and risk factors for $\mathrm{PN}$, defined by monofilament insensitivity, in middle-aged and older adults with and without diabetes from NHANES and ARIC.

\section{Methods}

Study populations. The NHANES are cross-sectional complex samples of the US civilian non-institutionalized population conducted by the National Center for Health Statistics. We examined data from black and white participants from NHANES 1999-2004, which included a standardized monofilament exam in participants aged 40 years and older. Among the 5771 NHANES participants aged $\geq 40$ years of age who had monofilament testing data available, we excluded those who were missing any variables of interest $(\mathrm{N}=578)$. NHANES study protocols were approved by the Institutional Review Board of the National Center for Health Statistics. All participants provided written informed consent. All research was performed in accordance with the Declaration of Helsinki.

ARIC is a community-based study of 15,792 adults enrolled between 1987 and 1989 from four US communities (Forsyth County, North Carolina; Jackson, Mississippi; Minneapolis, Minnesota; and Washington County, Maryland) and followed prospectively with serial visits. We used ARIC visit 6 data (collected between 2016 and 2017) for the current study because this visit included a standardized monofilament assessment. Among the 4003 black and white participants who attended ARIC visit 6, we excluded participants who were missing monofilament testing information $(\mathrm{N}=386)$, and those who were missing any other variables of interest $(\mathrm{N}=255)$. The ARIC study was approved by the Institutional Review Boards at each study site and informed consent was obtained from all participants.

Measurement of peripheral neuropathy using monofilament testing. In both NHANES and ARIC, the lower extremity monofilament exam was performed by trained technicians using a standard monofilament (5.07 Semmes-Weinstein nylon monofilament mounted on a plastic handle, delivering approximately a 10-g filament force) to apply slight pressure to the bottom of each participant's feet at the following three sites: (1) plantar-first metatarsal head; (2) plantar-fifth metatarsal head; and (3) plantar-hallux. If the participant's first response at a site was correct, the test was not repeated at that site. If the participant could not correctly identify when the pressure was applied, the test was repeated at that site for up to two times until a total of two similar responses were obtained (up to three tests at each site). A site was defined as insensate if two incorrect or undeterminable responses were given by the participant. PN was defined as having at least one insensate site on the left or right foot, corresponding to a reduced sensation to touch.

Of note, there was a monofilament examination instrument change during the early part of ARIC visit 6 (October 10th, 2016) due to the discontinuation by the manufacture of previous instrument (5.07 AliMed reusable nylon Semmes-Weinstein Monofilament). The effect of this instrument change was evaluated with a crossover study of 80 participants (20 from each ARIC Field Center). The results showed that there was no significant insensate classification or prevalence of PN differences between the two instruments.

Other variables. In NHANES, age, sex, race, education, smoking status, and drinking status were selfreported. Diabetes was defined as self-reported doctor-diagnosed diabetes, current glucose-lowering medication use, or $\mathrm{HbAlc} \geq 6.5 \%$. Among those without diabetes, prediabetes was defined as HbAlc level between $5.7 \%$ and $6.4 \%$ and normal was defined as $\mathrm{HbAlc}<5.7 \%$. Body mass index (BMI) was calculated as weight (kilograms) divided by squared height $\left(\mathrm{m}^{2}\right)$. Cardiovascular disease was defined as self-reported doctor diagnosed history of coronary heart disease, heart attack, or stroke. Hypertension was defined as systolic blood pressure $(\mathrm{SBP}) \geq 140 \mathrm{mmHg}$, diastolic blood pressure (DBP) $\geq 90 \mathrm{mmHg}$, or taking blood pressure control medication. Hypercholesterolemia was defined as total cholesterol $\geq 240 \mathrm{mg} / \mathrm{dL}$ or taking cholesterol control medication. Peripheral artery disease was defined as left or right ankle brachial index $(\mathrm{ABI})<0.9$. Cancer was defined as selfreported doctor diagnosed any cancer or malignancy other than melanoma skin cancer.

In ARIC, sex, race and education were ascertained at visit 1 (1987-1989). Unless otherwise noted, all other data used in the present study were collected at visit 6 (2016-2017). Age, smoking status and drinking status were self-reported. Diabetes was defined as self-reported doctor-diagnosed diabetes, current glucose-lowering medication use, or $\mathrm{HbAlc} \geq 6.5 \%$ at visit 6 . Pre-diabetes was defined as HbAlc level between $5.7 \%$ and $6.4 \%$ among those without diabetes. BMI was calculated as weight (kilograms) divided by squared height $\left(\mathrm{m}^{2}\right)$. Cardiovascular disease was defined as any occurrence of coronary heart disease, stroke, or heart failure, which included any validated hospitalized myocardial infarction, fatal coronary heart disease, cardiac procedure or electrocardiogram myocardial infarction, hospitalization or death due to heart failure, or definite or probable stroke at or prior to visit 6. Hypertension was defined as $\mathrm{SBP} \geq 140 \mathrm{mmHg}, \mathrm{DBP} \geq 90 \mathrm{mmHg}$, or taking blood pressure control medication. Hypercholesterolemia was defined as total cholesterol $\geq 240 \mathrm{mg} / \mathrm{dL}$, or taking cholesterol control medication. Peripheral artery disease was defined as left or right $\mathrm{ABI}<0.9$. SBP, DBP, total cholesterol and ABI information were collected at visit 6 . Cancer was defined as any invasive cancer and cancer deaths, which included 
adjudicated bladder, breast, colorectal, liver, lung, pancreatic and prostate cancer, and other non-adjudicated cancers, but not melanoma skin cancer, from cancer registry and death certificate at or prior to visit 6 .

Statistical analyses. We examined the characteristics of US adults from NHANES (1999-2004) by two age categories, approximately middle-aged (40-69 years) and older aged ( $\geq 70$ years), and ARIC visit 6 (2016-2017) participants (all of whom were $\geq 70$ years of age). The age categories for NHANES were chosen to match the older age range of ARIC participants at visit 6 (i.e. $\geq 70$ years of age). We estimated the age-, sex- and race-adjusted prevalence and standard errors of $\mathrm{PN}$ overall and by participant characteristics for the above two age groups in NHANES and ARIC visit 6 separately. We used the logistic regression models to evaluate the age-, sex- and raceadjusted associations of various participant characteristics with PN. We also used logistic regression to identify risk factors associated with PN after mutually adjusting for all variables. Of note, the ABI and cancer variables had a high proportion of missing. Thus, analyses of these data were conducted in a smaller number of participants $(\mathrm{N}=4419$ for peripheral artery disease in NHANES; $\mathrm{N}=2971$ for peripheral artery disease in ARIC; and $\mathrm{N}=3136$ for cancer in ARIC). Finally, we used logistic regression to evaluate the age, sex, and race-adjusted continuous association of PN with diabetes duration categories ( $0-4$ years, 5-14 years, $15-24$ years, and $\geq 25$ years).

We performed all analyses using Stata, version 15.1 (StataCorp) with $\mathrm{P}<0.05$ denoting statistical significance. For all analyses of NHANES data, we incorporated sampling weights in the Stata survey commands to obtain unbiased estimates from the complex sampling design and used Taylor series (linearization) method to estimate the standard errors, as recommended by the National Center for Health Statistics analysis guidelines. All estimates from NHANES presented in the results and the tables/figures are nationally representative of the US adult population in the age groups examined. Estimates from ARIC are unweighted.

\section{Results}

Characteristics of study participants. Overall, 5193 middle-aged (40-69 years, $\mathrm{N}=3578$ ) and older ( $\geq 70$ years, $N=1615$ ) NHANES participants and 3362 older ( $\geq 70$ years) ARIC participants underwent standardized lower extremity monofilament testing. The ARIC Study oversampled African Americans so more participants were black as a function of the study design (20.4\% in ARIC vs. 6.5\% US adults in NHANES) and ARIC participants were older (i.e., larger percentage of the ARIC population was $\geq 80$ years of age compared to US adults: $42.0 \%$ vs. $30.6 \%$ ) (Table 1). The prevalence of prediabetes was similar in older US adults and in the ARIC Study population, whereas diabetes was more common in ARIC participants $\geq 70$ years compared to US adults in this age group $(31.8 \%$ vs $16.8 \%)$.

Prevalence of and risk factors for peripheral neuropathy. The overall prevalence of PN defined by monofilament insensitivity in the general US population aged 40 years or older was $13.5 \%$, equivalent to 18.6 million US adults in 2010. The overall prevalence of PN in adults aged 40 or older was $28.4 \%$ in persons with diabetes ( 4.2 million) and $11.8 \%$ in those without diabetes (14.4 million). The age-, sex-, and raceadjusted estimated prevalence of PN in US adults was $10.4 \pm 0.5 \%$ in those $40-69$ years and $26.8 \pm 1.1 \%$ among those $\geq 70$ years. In the ARIC Study, the prevalence of PN was $34.4 \pm 0.8 \%$. The prevalence of PN was higher at older ages (Fig. 1), with $34.2 \pm 1.8 \%$ and $42.4 \pm 1.3 \%$ of NHANES and ARIC participants $\geq 80$ years of age affected, respectively (Table 2 ).

In both populations, PN was more common in adults with diabetes, especially among those with longstanding disease (Fig. 2). In general, risk factors for PN were similar in adults 40-69 compared to older adults and between older US adults and ARIC participants (Table 3). Age, sex, and race were strongly associated with $\mathrm{PN}$, with males and blacks having a substantially higher prevalence compared to females and whites in both studies. Diabetes was also an important risk factor. The association of diabetes with PN was highest for middleaged adults and for adults with diabetes $\geq 10$ years duration, although the association of diabetes $<10$ years duration with PN was also significant for all groups. Other key risk factors for PN included higher body mass index, greater height, lower education, and peripheral artery disease (in middle-aged US adults and older adults in ARIC). Never drinkers were more likely to have PN compared to current light/moderate drinkers. Prevalent cardiovascular disease, hypertension, and chronic kidney disease were moderately associated with PN.

Simultaneous adjustment for all cardiovascular and diabetes factors did not substantially alter our findings, with a few exceptions (Supplemental Table 1). First, the associations of black race and hypertension with PN were no longer significant after adjustment for other risk factors. Second, only long-standing diabetes ( $\geq 10$ years duration) remained associated with PN after multivariable adjustment.

\section{Discussion}

Based on data from NHANES and ARIC, we found that the age, sex, and race-adjusted prevalence of PN defined by monofilament sensitivity for adults aged 70 years or older was $26.8 \%$ in US adults and $34.4 \%$ in the ARIC Study compared to $10.4 \%$ in US adults aged $40-69$ years. Risk factors associated with PN in both NHANES and ARIC included long-standing diabetes, older age, male sex, black race, higher body mass index, and greater height. There were weaker associations of hypertension, prevalent cardiovascular disease, prevalent chronic kidney disease, and peripheral artery disease, particularly among middle-aged US adults and older ARIC participants. Notably, although diabetes was significantly associated with PN for all groups, PN was also present in a large proportion of adults without diabetes in both the US population and ARIC. This finding suggests that PN defined by monofilament sensitivity may affect a greater proportion of adults without diabetes than previously appreciated.

The higher prevalence of PN among older ARIC participants as compared to NHANES may be due to several factors. First, the ARIC and NHANES populations are different. Participants in ARIC had more comorbidities 


\section{Age, years}

\begin{tabular}{|l|l|}
\hline $40-49$ & $43.0 \%$ \\
\hline $50-59$ & $34.0 \%$ \\
\hline $60-69$ & $23.0 \%$ \\
\hline $70-74$ & - \\
\hline $75-79$ & - \\
\hline$\geq 80$ & - \\
\hline Male & $49.7 \%$ \\
\hline Black & $10.7 \%$ \\
\hline Education & \\
\hline
\end{tabular}

\begin{tabular}{|l|l}
\hline- & - \\
\hline- & - \\
\hline $38.3 \%$ & - \\
\hline $31.1 \%$ & $14.8 \%$ \\
\hline $30.6 \%$ & $43.2 \%$ \\
\hline $41.5 \%$ & $42.0 \%$ \\
\hline $6.5 \%$ & $41.1 \%$ \\
\hline
\end{tabular}

Education

\begin{tabular}{|l|l|}
\hline Less than high school & $13.8 \%$ \\
\hline
\end{tabular}

\begin{tabular}{|l|l|l|}
\hline High school or vocational school & $13.8 \%$ & $26.5 \%$ \\
\hline College and above & $59.7 \%$ \\
\hline
\end{tabular}

\begin{tabular}{|l|l|}
\hline $29.3 \%$ & $11.1 \%$ \\
\hline $30.9 \%$ & $41.3 \%$ \\
\hline $39.8 \%$ & $47.6 \%$ \\
\hline
\end{tabular}

Diabetes status

\begin{tabular}{|l|l|l|l}
\hline Normal & $77.1 \%$ & $59.0 \%$ & $43.4 \%$ \\
\hline Pre-diabetes & $13.6 \%$ & $24.2 \%$ & $24.8 \%$ \\
\hline Diabetes $(<10$ years duration) & $6.3 \%$ & $8.9 \%$ & $23.0 \%$ \\
\hline Diabetes $(\geq 10$ years duration) & $3.1 \%$ & $7.9 \%$ & $8.8 \%$ \\
\hline
\end{tabular}

Body mass index, $\mathrm{kg} / \mathrm{m}^{2}$

\begin{tabular}{l}
\hline $0-24.9$ \\
\hline $25-29.9$ \\
\hline$\geq 30$
\end{tabular}

\begin{tabular}{|l|l|}
\hline $28.6 \%$ \\
\hline $36.3 \%$ \\
\hline $35.1 \%$
\end{tabular}

\begin{tabular}{|l|}
\hline $33.6 \%$ \\
\hline $40.8 \%$ \\
\hline $25.6 \%$
\end{tabular}

\begin{tabular}{|l|}
\hline $28.9 \%$ \\
\hline $38.9 \%$ \\
\hline $32.2 \%$
\end{tabular}

Sex-specific height quartile

\begin{tabular}{|l|l|}
\hline Q1 \\
\hline Q2 \\
\hline Q3 \\
\hline Q4
\end{tabular}

\begin{tabular}{|l|l|}
\hline $15.5 \%$ \\
\hline $23.5 \%$ \\
\hline $28.0 \%$ \\
\hline $33.0 \%$
\end{tabular}

\begin{tabular}{|l|l|}
\hline $39.5 \%$ & $23.9 \%$ \\
\hline $27.4 \%$ & $23.0 \%$ \\
\hline $20.1 \%$ & $25.1 \%$ \\
\hline $13.0 \%$ & $28.0 \%$ \\
\hline
\end{tabular}

Smoking status

\begin{tabular}{|l|l|}
\hline Never & $44.6 \%$ \\
\hline Former & $32.4 \%$ \\
\hline Current & $23.0 \%$ \\
\hline
\end{tabular}

\begin{tabular}{|l|l|}
\hline $51.0 \%$ & $45.0 \%$ \\
\hline $42.2 \%$ & $48.3 \%$ \\
\hline $6.8 \%$ & $6.7 \%$ \\
\hline
\end{tabular}

Drinking status

\begin{tabular}{|l|l|l|l|}
\hline Never & $9.9 \%$ & $20.6 \%$ & $20.4 \%$ \\
\hline Former & $19.7 \%$ & $30.7 \%$ & $28.3 \%$ \\
\hline Current light/moderate drinker & $40.2 \%$ & $40.3 \%$ & $46.5 \%$ \\
\hline Current heavier drinker & $30.2 \%$ & $8.4 \%$ & $4.8 \%$ \\
\hline Prevalent cardiovascular disease & $8.1 \%$ & $24.8 \%$ & $20.0 \%$ \\
\hline Hypertension & $37.1 \%$ & $74.5 \%$ & $84.0 \%$ \\
\hline Hypercholesterolemia & $33.4 \%$ & $45.2 \%$ & $60.5 \%$ \\
\hline Prevalent chronic kidney disease & $11.4 \%$ & $50.4 \%$ & $41.2 \%$ \\
\hline Peripheral artery disease & $3.3 \%$ & $17.0 \%$ & $5.2 \%$ \\
\hline Cancer $^{\mathrm{b}}$ & $9.0 \%$ & $25.2 \%$ & $15.9 \% \dagger$ \\
\hline
\end{tabular}

Table 1. Characteristics of US adults aged 40-69 and $\geq 70$ years (NHANES, 1999-2004) and ARIC

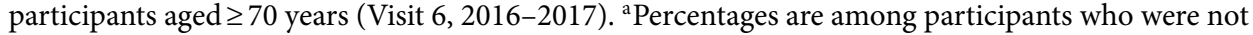
missing data for peripheral artery disease: $N=3215$ in NHANES aged 40-69 years, $N=1204$ in NHANES aged $\geq 70$ years, and $\mathrm{N}=2971$ in ARIC visit 6 . ${ }^{b}$ Percentage for the ARIC study is among participants who were not missing cancer status at ARIC visit $6, \mathrm{~N}=3136$.

than in NHANES, potentially due to differences in study recruitment and selection. Second, a higher proportion of older ARIC versus NHANES participants had diabetes, the most commonly described risk factor for PN.

We observed a strong age-related increase in the prevalence of PN. There are a several studies documenting an association of age with PN among adults with diabetes ${ }^{5,22}$. Although other reports on the epidemiology of $\mathrm{PN}$ in older adults in the general population are scarce, there are a several studies documenting strong associations of age with PN among adults with diabetes. Among 6487 adults with diabetes in the United Kingdom, the prevalence of PN was approximately $5 \%$ in the $20-29$ year age group, compared to $44 \%$ in the $70-79$ year age 


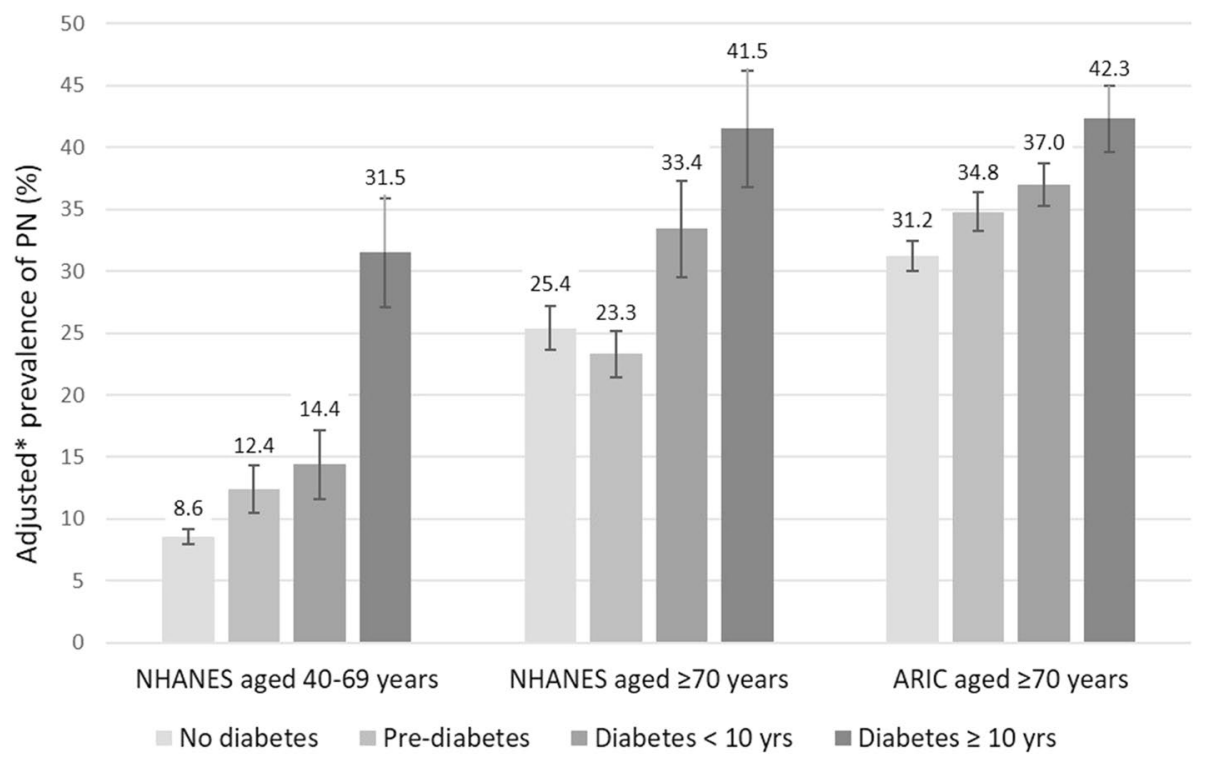

*Adjusted for age, sex, and race

Figure 1. Age, sex, and race-adjusted prevalence of peripheral neuropathy stratified by diabetes status in US adults aged 40-69 and $\geq 70$ years (NHANES, 1999-2004) and ARIC participants aged $\geq 70$ years (Visit 6, 2016-2017).

group $^{5}$. Cabezas-Cerrato performed a cross-sectional study of PN among 2644 adults with diabetes in Spain, and reported that $30 \%$ of those aged $70-74$ years had $\mathrm{PN}^{22}$. These estimates are similar to the prevalence estimates that we report among older adults in NHANES and ARIC, although the variability among studies likely reflects heterogeneity in recruitment approaches, the populations studied, and diagnostic protocols for PN.

Our study confirms previous findings, but also demonstrates that PN is highly prevalent in older adults without diabetes. The American Diabetes Association recommends annually assessment for PN in all adults with diabetes ${ }^{18}$, but PN screening with monofilament testing is not routinely performed in adults without diabetes. In a separate study, we recently demonstrated a strong and independent association of PN with mortality in both persons with and without diabetes ${ }^{9}$. Taken as whole, our results suggest that the high prevalence of $\mathrm{PN}$ is common and is an underrecognized risk factor for mortality in the general population.

Some of the risk factors with PN we identified in older adults have been previously described in younger populations, including body mass index, hypertension, history of cardiovascular disease, and peripheral artery disease $^{23-25}$. Tesfaye et al. performed a prospective study of 1172 patients with type 1 diabetes with 7.3 years of follow-up (mean age 32.7 years), and found that the risk of PN was independently associated with duration of diabetes, glucose control, body mass index, smoking, and prevalent cardiovascular disease ${ }^{23}$. Olaiya et al. recently performed a cross-sectional study of middle-aged adult volunteers (mean age 41.9 years), and found that age, male sex, body mass index, heart rate, mean arterial pressure, and family history of diabetes or cardiovascular diseases were important risk factors ${ }^{26}$. We did not find an association of hypercholesterolemia with PN among older adults, but we did find strong differences by sex and race. There was also an inverse association between smoking and PN in older adults in NHANES. While smoking and peripheral neuropathy were positively associated in a recent meta-analysis ${ }^{27}$, there are prior studies that report an inverse relationship similar to ours ${ }^{28,29}$. This may be due to a survival bias or possibly a quitting effect, where current smoking is more common among those with better health or among surviving older patients ${ }^{29}$.

The prevalence of PN was high among adults with diabetes and positively associated with longer duration of diabetes. This finding is consistent with previously published PN data from the general population ${ }^{2,16,17}$. Prior data also show convincing evidence that a longer duration of diabetes is associated with a higher prevalence of peripheral neuropathy ${ }^{23,30}$, and we found a similar association of diabetes duration with PN in both middle-aged and older adults. The stronger association of PN with diabetes in middle-aged compared to older adults observed in our study is consistent with the large literature comparing the contribution of vascular risk factors in mid-life to those in old-age $\mathrm{e}^{31-35}$. Older adults have substantially more cardiometabolic disease and risk factors compared to middle-aged adults ${ }^{13}$; thus, any single risk factor tends to have relatively lower effect in older as compared to younger ages. It is also possible that PN in older adults represents a microvascular etiology of disease that is less dependent on hyperglycemia than other cardiovascular risk factors. Consistent with this notion, we have previously shown strong associations of cardiac troponin $\mathrm{T}$ and N-terminal (NT)-pro hormone BNP with PN in older adults both with and without diabetes ${ }^{36}$.

Because PN is classically attributed to hyperglycemia ${ }^{37}$, the high prevalence of PN in non-diabetic adults in our study is novel and warrants attention. PN is a side effect of chemotherapy and can result from chronic alcoholism, viral infections, spinal cord injury, or radiculopathy as well ${ }^{38-41}$. However, these conditions are uncommon in the general population and are unlikely to explain the high prevalence of $\mathrm{PN}$ that we observed in 


\begin{tabular}{|c|c|c|c|}
\hline & \multirow{2}{*}{\begin{tabular}{|l|} 
Aged $40-69$ years \\
US adults (NHANES) $(\mathrm{N}=3578)$ \\
\end{tabular}} & \multicolumn{2}{|l|}{ Aged 70 years or older } \\
\hline & & US adults (NHANES) $(\mathrm{N}=1615)$ & ARIC (Visit 6) ( $N=3362)$ \\
\hline Overall & $10.4(0.5)$ & $26.8(1.1)$ & $34.4(0.8)$ \\
\hline \multicolumn{4}{|l|}{ Age } \\
\hline $40-49$ & $6.4(0.6)$ & - & \\
\hline $50-59$ & $10.9(0.9)$ & - & \\
\hline $60-69$ & $17.5(1.3)$ & - & \\
\hline $70-74$ & - & $20.7(1.9)$ & $24.5(1.9)$ \\
\hline $75-79$ & - & $27.5(2.1)$ & $30.1(1.2)$ \\
\hline$\geq 80$ & - & $34.2(1.8)$ & $42.4(1.3)$ \\
\hline \multicolumn{4}{|l|}{ Sex } \\
\hline Female & $6.7(0.6)$ & $20.5(1.4)$ & $25.3(1.0)$ \\
\hline Male & $14.2(0.7)$ & $36.0(1.6)$ & $47.6(1.3)$ \\
\hline \multicolumn{4}{|l|}{ Race } \\
\hline White & $10.0(0.5)$ & $26.2(1.2)$ & $33.3(0.9)$ \\
\hline Black & $14.0(1.0)$ & $36.2(4.0)$ & $39.1(1.8)$ \\
\hline \multicolumn{4}{|l|}{ Education } \\
\hline Less than high school & $14.6(1.8)$ & $28.5(2.5)$ & $43.3(2.5)$ \\
\hline High school or vocational school & $11.5(0.9)$ & $26.4(2.5)$ & $33.5(1.2)$ \\
\hline College and above & $8.8(0.7)$ & $26.0(1.9)$ & $33.2(1.1)$ \\
\hline \multicolumn{4}{|l|}{ Diabetes status } \\
\hline Normal & $8.6(0.6)$ & $25.4(1.8)$ & $31.2(1.2)$ \\
\hline Pre-diabetes & $12.4(1.9)$ & $23.3(1.9)$ & $34.8(1.6)$ \\
\hline Diabetes $(<10$ years duration $)$ & $14.4(2.8)$ & $33.4(3.9)$ & $37.0(1.7)$ \\
\hline Diabetes ( $\geq 10$ years duration) & $31.5(4.4)$ & $41.5(4.7)$ & $42.3(2.7)$ \\
\hline \multicolumn{4}{|l|}{ Body mass index, $\mathrm{kg} / \mathrm{m}^{2}$} \\
\hline $0-24.9$ & $8.2(1.0)$ & $22.4(1.8)$ & $31.0(1.4)$ \\
\hline $25-29.9$ & $9.3(1.0)$ & $26.0(1.8)$ & $32.0(1.2)$ \\
\hline$\geq 30$ & $13.3(1.1)$ & $34.4(2.4)$ & $40.6(1.4)$ \\
\hline \multicolumn{4}{|l|}{ Sex-specific height quartile } \\
\hline Q1 & $7.5(0.9)$ & $20.6(1.5)$ & $27.5(1.5)$ \\
\hline Q2 & $7.5(0.9)$ & $26.8(2.1)$ & $27.8(1.6)$ \\
\hline Q3 & $10.3(1.0)$ & $30.5(2.5)$ & $34.9(1.6)$ \\
\hline Q4 & $14.5(1.0)$ & $41.6(3.5)$ & $45.4(1.6)$ \\
\hline \multicolumn{4}{|l|}{ Smoking status } \\
\hline Never & $10.3(0.8)$ & $27.8(1.8)$ & $34.9(1.2)$ \\
\hline Former & $9.8(1.0)$ & $27.7(1.7)$ & $33.8(1.1)$ \\
\hline Current & $11.7(1.1)$ & $15.2(3.4)$ & $35.9(3.1)$ \\
\hline \multicolumn{4}{|l|}{ Drinking status } \\
\hline Never & $14.0(1.9)$ & $32.4(3.3)$ & $37.6(1.9)$ \\
\hline Former & $11.7(0.8)$ & $28.8(2.4)$ & $35.4(1.5)$ \\
\hline Current light/moderate drinker & $8.7(0.8)$ & $23.8(1.7)$ & $33.1(1.2)$ \\
\hline Current heavier drinker & $10.8(1.0)$ & $21.8(2.7)$ & $28.8(3.5)$ \\
\hline \multicolumn{4}{|l|}{ Prevalent cardiovascular disease } \\
\hline No & $10.1(0.5)$ & $25.2(1.6)$ & $33.6(0.9)$ \\
\hline Yes & $13.2(2.2)$ & $31.6(2.7)$ & $37.5(1.8)$ \\
\hline \multicolumn{4}{|l|}{ Hypertension } \\
\hline No & $9.4(0.6)$ & $26.0(1.6)$ & $30.3(2.0)$ \\
\hline Yes & $11.8(0.9)$ & $27.2(1.3)$ & $35.2(0.9)$ \\
\hline \multicolumn{4}{|l|}{ Hypercholesterolemia } \\
\hline No & $10.1(0.6)$ & $29.3(1.6)$ & $34.2(1.3)$ \\
\hline Yes & $11.1(1.1)$ & $23.6(1.4)$ & $34.6(1.0)$ \\
\hline \multicolumn{4}{|l|}{ Prevalent chronic kidney disease } \\
\hline No & $9.7(0.5)$ & $25.3(1.9)$ & $31.7(1.0)$ \\
\hline Yes & $15.2(1.7)$ & $28.3(1.9)$ & $38.0(1.3)$ \\
\hline \multicolumn{4}{|l|}{ Peripheral artery disease $^{a}$} \\
\hline No & $9.5(0.5)$ & $22.7(1.4)$ & $33.6(0.9)$ \\
\hline Continued & & & \\
\hline
\end{tabular}




\begin{tabular}{|l|l|l|l|}
\hline \multicolumn{2}{|l|}{} & Aged 40-69 years & \multicolumn{2}{l|}{ Aged 70 years or older } \\
\cline { 2 - 4 } & US adults (NHANES) (N=3578) & US adults (NHANES) (N=1615) & ARIC (Visit 6) (N=3362) \\
\hline Yes & $17.1(2.8)$ & $22.6(2.7)$ & $44.3(3.8)$ \\
\hline Cancer ${ }^{\mathrm{b}}$ & \multicolumn{3}{|l}{} \\
\hline No & $10.2(0.5)$ & $26.0(1.5)$ & $34.0(0.9)$ \\
\hline Yes & $12.0(2.0)$ & $29.3(2.2)$ & $38.0(2.1)$ \\
\hline
\end{tabular}

Table 2. Age, sex, and race-adjusted prevalence [\% (SE)] of peripheral neuropathy by demographic and risk factor categories among US adults aged $40-69$ and $\geq 70$ years (NHANES, 1999-2004) and ARIC participants aged $\geq 70$ years (Visit 6,2016-2017). a Prevalences are among participants who were not missing data for peripheral artery disease: $\mathrm{N}=3215$ in NHANES aged 40-69 years, $\mathrm{N}=1204$ in NHANES aged $\geq 70$ years, and $\mathrm{N}=2971$ in ARIC visit 6 . ${ }^{\mathrm{b}}$ Prevalence for the ARIC study is among participants who were not missing cancer status in ARIC visit 6, $\mathrm{N}=3136$.
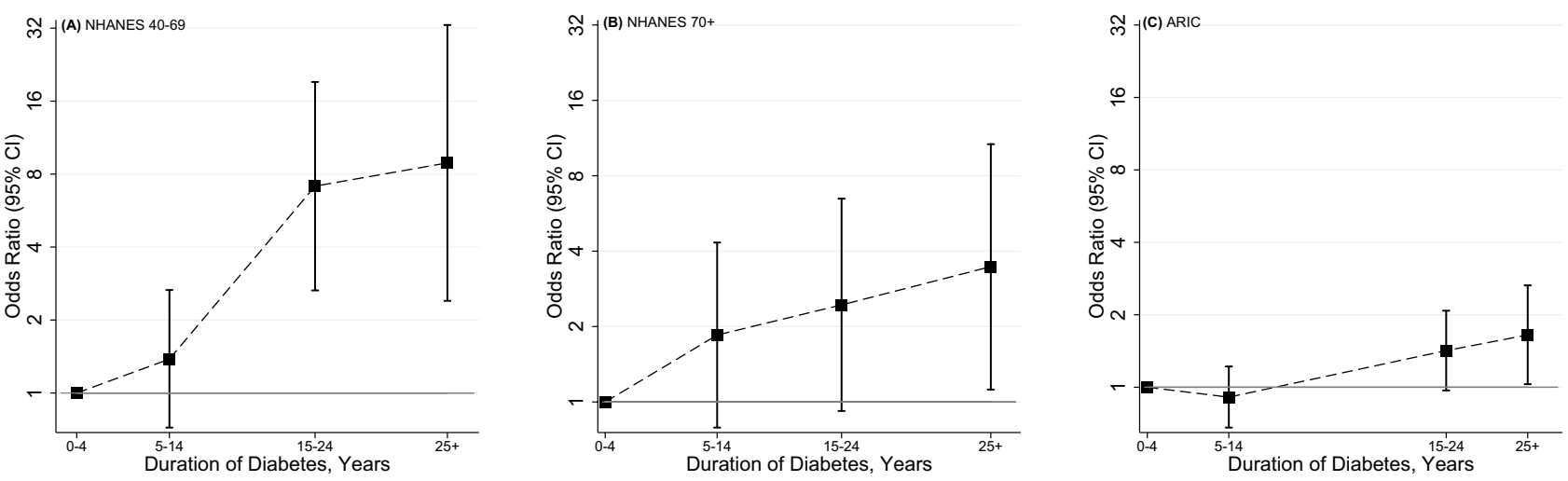

Figure 2. Association of peripheral neuropathy with duration of diabetes among US adults aged 40-69 (panel A) and $\geq 70$ years (panel B) (NHANES, 1999-2004) and ARIC participants aged $\geq 70$ years (panel C) (Visit 6, 2016-2017). Adjusted associations for duration of diabetes with peripheral neuropathy in ARIC (2016-2017) and NHANES (1999-2004). Odds ratios were from logistic regression models adjusted for age, sex and race. Duration of diabetes was modelled as a categorical variable: $0-4$ years, 5-14 years, 15-24 years and 25 years and more. Odds ratios and $95 \%$ confidence intervals were plotted at the median of each diabetes duration category.

the NHANES and ARIC study populations. We did find a slightly higher prevalence of PN among adults with a history of cancer in our study. Peripheral nerve dysfunction has been reported to occur in $25-66 \%$ of chronic alcoholics in the $\mathrm{US}^{41}$, but this association is unlikely to be generalizable to more moderate drinking. We did not find an association of former drinking with PN in our study; in fact, adults with no history of drinking had the highest prevalence of PN. The explanation for this finding is unclear, but may reflect differences between drinkers and non-drinkers and that moderate drinking is typically associated with beneficial cardiometabolic risk $^{41,42}$. Regardless of the etiology, the high prevalence of non-diabetic PN among adults $\geq 70$ years of age suggests that there may be an unexplained loss of peripheral sensation among older adults (i.e. idiopathic PN) that is underrecognized. Notably, there are no formal guidelines for foot examinations or monofilament testing among adults without diabetes. The vast majority of data available describing PN risk factors and outcomes are in populations of adults with diabetes ${ }^{43-46}$. More studies are needed to understand the underlying etiology and clinical implications of idiopathic PN in older adults.

Novel aspects of our study include the characterization of the epidemiology and risk factors associated PN among middle-aged and older adults, separately, and stratified by diabetes status. There have been a number of cohort studies that have previously reported the prevalence and risk factors associated with PN. Most of these studies have focused on either middle-aged adults or older adult men or women (separately). Our study adds to the existing literature by describing the prevalence of and risk factors associated with PN, defined by monofilament insensitivity, among older adults ( $>70$ years of age) both with and without diabetes. These data are important to our understanding of the epidemiology of PN, and show that the risk factors for PN in middle age are not entirely the same as the risk factors for PN in older adults.

The limitations of our study include a lack of symptom-based data in both NHANES and ARIC. Our evaluation of peripheral sensation was limited to monofilament testing only; neither NHANES or ARIC used nerve conduction studies, vibration threshold testing, or patient-reported questionnaires such as the Michigan Neuropathy Screening Instrument ${ }^{47,48}$ to capture symptoms. As a result, our findings are limited to an evaluation of PN with decreased lower extremity sensation only, which may be an advanced form of the disease ${ }^{19}$. There were also some minor differences in covariate assessments between NHANES and ARIC. Variation in covariate definitions may explain some of the differences in associations (e.g. prevalent cardiovascular disease). However, 


\begin{tabular}{|c|c|c|c|}
\hline & \multirow{2}{*}{\begin{tabular}{|l|} 
Aged $40-69$ years \\
US adults (NHANES) \\
OR $(95 \%$ CI $)$ \\
\end{tabular}} & \multicolumn{2}{|l|}{ Aged $\geq 70$ years } \\
\hline & & $\begin{array}{l}\text { US adults (NHANES) } \\
\text { OR }(95 \% \mathrm{CI})\end{array}$ & $\begin{array}{l}\text { ARIC (Visit 6) } \\
\text { OR (95\% CI) }\end{array}$ \\
\hline \multicolumn{4}{|l|}{ Age in years } \\
\hline $40-49$ & 1 (Ref) & - & - \\
\hline $50-59$ & $1.81(1.38-2.37)$ & - & - \\
\hline $60-69$ & $3.20(2.38-4.31)$ & - & - \\
\hline $70-74$ & - & 1 (Ref) & 1 (Ref) \\
\hline $75-79$ & - & $1.47(1.06-2.04)$ & $1.35(1.06-1.71)$ \\
\hline$\geq 80$ & - & $2.04(1.51-2.75)$ & $2.38(1.87-3.02)$ \\
\hline \multicolumn{4}{|l|}{ Sex } \\
\hline Female & 1 (Ref) & 1 (Ref) & 1 (Ref) \\
\hline Male & $2.36(1.94-2.86)$ & $2.22(1.79-2.75)$ & $2.75(2.37-3.20)$ \\
\hline \multicolumn{4}{|l|}{ Race } \\
\hline White & 1 (Ref) & 1 (Ref) & 1 (Ref) \\
\hline Black & $1.49(1.20-1.85)$ & $1.63(1.11-2.39)$ & $1.32(1.09-1.58)$ \\
\hline \multicolumn{4}{|l|}{ Education } \\
\hline College and above & 1 (Ref) & 1 (Ref) & 1 (Ref) \\
\hline High school or vocational school & $1.35(1.01-1.81)$ & $1.02(0.71-1.46)$ & $1.02(0.87-1.19)$ \\
\hline Less than high school & $1.81(1.26-2.58)$ & $1.14(0.78-1.67)$ & $1.60(1.25-2.03)$ \\
\hline \multicolumn{4}{|l|}{ Diabetes status } \\
\hline Normal & 1 (Ref) & 1 (Ref) & 1 (Ref) \\
\hline Pre-diabetes & $1.53(1.01-2.30)$ & $0.89(0.64-1.22)$ & $1.19(0.99-1.44)$ \\
\hline Diabetes $(<10$ years duration $)$ & $1.82(1.07-3.10)$ & $1.50(1.00-2.27)$ & $1.32(1.09-1.60)$ \\
\hline Diabetes ( $\geq 10$ years duration) & $5.26(3.27-8.46)$ & $2.17(1.33-3.54)$ & $1.68(1.29-2.20)$ \\
\hline \multicolumn{4}{|l|}{ Body mass index, $\mathrm{kg} / \mathrm{m}^{2}$} \\
\hline $0-24.9$ & 1 (Ref) & 1 (Ref) & 1 (Ref) \\
\hline $25-29.9$ & $1.14(0.77-1.69)$ & $1.22(0.93-1.61)$ & $1.05(0.87-1.27)$ \\
\hline$\geq 30$ & $1.74(1.23-2.48)$ & $1.87(1.39-2.51)$ & $1.58(1.30-1.92)$ \\
\hline \multicolumn{4}{|l|}{ Sex-specific height quartile } \\
\hline Q1 & 1 (Ref) & 1 (Ref) & 1 (Ref) \\
\hline Q2 & $0.99(0.68-1.44)$ & $1.43(1.11-1.85)$ & $1.02(0.81-1.28)$ \\
\hline Q3 & $1.43(1.05-1.93)$ & $1.74(1.27-2.39)$ & $1.46(1.17-1.81)$ \\
\hline Q4 & $2.15(1.54-3.00)$ & $2.91(2.04-4.14)$ & $2.36(1.91-2.91)$ \\
\hline \multicolumn{4}{|l|}{ Smoking status } \\
\hline Never & 1 (Ref) & 1 (Ref) & 1 (Ref) \\
\hline Former & $0.95(0.70-1.30)$ & $0.99(0.74-1.31)$ & $0.95(0.81-1.11)$ \\
\hline Current & $1.17(0.86-1.59)$ & $0.45(0.26-0.80)$ & $1.05(0.77-1.42)$ \\
\hline \multicolumn{4}{|l|}{ Drinking status } \\
\hline Current light/moderate drinker & 1 (Ref) & 1 (Ref) & 1 (Ref) \\
\hline Current heavier drinker & $1.28(0.93-1.76)$ & $0.89(0.60-1.32)$ & $0.80(0.55-1.17)$ \\
\hline Former & $1.41(1.07-1.84)$ & $1.31(0.93-1.84)$ & $1.11(0.93-1.33)$ \\
\hline Never & $1.74(1.21-2.49)$ & $1.56(1.06-2.30)$ & $1.24(1.01-1.52)$ \\
\hline \multicolumn{4}{|l|}{ Prevalent cardiovascular disease } \\
\hline No & 1 (Ref) & 1 (Ref) & 1 (Ref) \\
\hline Yes & $1.37(0.90-2.08)$ & $1.39(0.96-2.00)$ & $1.20(1.00-1.44)$ \\
\hline \multicolumn{4}{|l|}{ Hypertension } \\
\hline No & 1 (Ref) & 1 (Ref) & 1 (Ref) \\
\hline Yes & $1.30(1.02-1.67)$ & $1.07(0.86-1.32)$ & $1.27(1.03-1.58)$ \\
\hline \multicolumn{4}{|l|}{ Hypercholesterolemia } \\
\hline No & 1 (Ref) & 1 (Ref) & 1 (Ref) \\
\hline Yes & $1.12(0.84-1.48)$ & $0.74(0.59-0.92)$ & $1.02(0.88-1.19)$ \\
\hline \multicolumn{4}{|l|}{ Prevalent chronic kidney disease } \\
\hline No & 1 (Ref) & 1 (Ref) & 1 (Ref) \\
\hline Yes & $1.71(1.25-2.33)$ & $1.17(0.84-1.62)$ & $1.35(1.16-1.57)$ \\
\hline \multicolumn{4}{|l|}{ Peripheral artery disease $^{\mathrm{a}}$} \\
\hline No & 1 (Ref) & 1 (Ref) & 1 (Ref) \\
\hline Yes & $2.02(1.31-3.10)$ & $0.99(0.69-1.42)$ & $1.64(1.16-2.30)$ \\
\hline \multicolumn{4}{|l|}{ Continued } \\
\hline
\end{tabular}




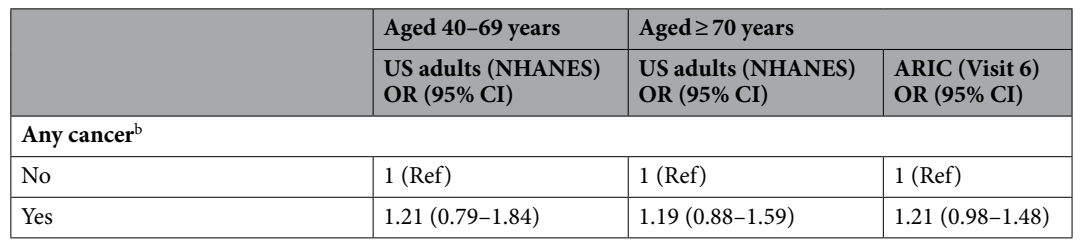

Table 3. Age-, sex-, and race-adjusted odds ratios [OR (95\% CI)] for the association of risk factors with peripheral neuropathy in US adults aged 40-69 and $\geq 70$ years (NHANES, 1999-2004) and ARIC participants

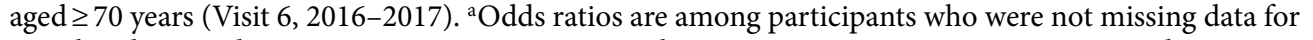
peripheral artery disease: $\mathrm{N}=3215$ in NHANES aged 40-69 years, $\mathrm{N}=1204$ in NHANES aged $\geq 70$ years, and $\mathrm{N}=2971$ in ARIC visit $6 .{ }^{\mathrm{b}}$ Odds ratio for ARIC is among participants who were not missing cancer status in ARIC visit 6, $\mathrm{N}=3136$.

both NHANES and ARIC used trained personnel and standardized approaches to data collection, and variable definitions were similar for most conditions. Importantly, PN was evaluated using the same monofilament testing protocols in both studies.

In conclusion, $\mathrm{PN}$ defined by monofilament insensitivity is highly prevalent in the general population, especially among older adults. Long-standing diabetes, male sex, and black race are strong risk factors for PN in both middle-aged and older adults in the general population. Older age is also closely associated with PN in adults with and without diabetes, the latter of which has previously been unrecognized. Future studies should evaluate prognosis in older adults with PN in the absence of diabetes, and determine whether screening for PN using monofilament testing in older adults, regardless of diabetes status, affects important clinical outcomes.

Received: 3 March 2021; Accepted: 25 August 2021

Published online: 27 September 2021

\section{References}

1. Watson, J. C. \& Dyck, P. J. Peripheral neuropathy: A practical approach to diagnosis and symptom management. Mayo Clin. Proc. 90, 940-951 (2015).

2. Ang, L., Jaiswal, M., Martin, C. \& Pop-Busui, R. Glucose control and diabetic neuropathy: Lessons from recent large clinical trials. Curr. Diabetes Rep. 14, 528 (2014).

3. Boulton, A. J. et al. Diabetic neuropathies: A statement by the American Diabetes Association. Diabetes Care 28, 956-962 (2005).

4. Iqbal, Z. et al. Diabetic peripheral neuropathy: Epidemiology, diagnosis, and pharmacotherapy. Clin. Ther. 40, 828-849 (2018).

5. Young, M. J., Boulton, A. J., MacLeod, A. F., Williams, D. R. \& Sonksen, P. H. A multicentre study of the prevalence of diabetic peripheral neuropathy in the United Kingdom hospital clinic population. Diabetologia 36, 150-154 (1993).

6. Dyck, P. J. et al. Variables influencing neuropathic endpoints: The Rochester Diabetic Neuropathy Study of Healthy Subjects. Neurology 45, 1115-1121 (1995).

7. Vileikyte, L. et al. Diabetic peripheral neuropathy and depressive symptoms: The association revisited. Diabetes Care 28, 2378-2383 (2005).

8. Koski, K., Luukinen, H., Laippala, P. \& Kivela, S. L. Risk factors for major injurious falls among the home-dwelling elderly by functional abilities A prospective population-based study. Gerontology 44, 232-238 (1998).

9. Hicks, C. W., Wang, D., Matsushita, K., Windham, B. G. \& Selvin, E. Peripheral neuropathy and all-cause and cardiovascular mortality in U.S. adults: A prospective cohort study. Ann. Intern. Med. 174, 167-174 (2021).

10. Doshi, S. et al. Chronic kidney disease as a risk factor for peripheral nerve impairment in older adults: A longitudinal analysis of Health, Aging and Body Composition (Health ABC) study. PLoS One 15, e0242406 (2020).

11. Dusendang, J. R. et al. The association between perceived discrimination in midlife and peripheral neuropathy in a populationbased cohort of women: The Study of Women's Health Across the Nation. Ann. Epidemiol. 37, 10-16 (2019).

12. Lange-Maia, B. S. et al. Sensorimotor peripheral nerve function and physical activity in older men. J. Aging Phys. Act. 24, 559-566 (2016).

13. van der Velde, J. et al. Cardiometabolic risk factors as determinants of peripheral nerve function: The Maastricht Study. Diabetologia 63, 1648-1658 (2020).

14. Ward, R. E. et al. Peripheral nerve function and lower extremity muscle power in older men. Arch. Phys. Med. Rehabil. 95, 726-733 (2014).

15. Ylitalo, K. R., Herman, W. H. \& Harlow, S. D. Performance-based physical functioning and peripheral neuropathy in a populationbased cohort of women at midlife. Am. J. Epidemiol. 177, 810-817 (2013).

16. Gregg, E. W. et al. Prevalence of lower extremity diseases associated with normal glucose levels, impaired fasting glucose, and diabetes among U.S. adults aged 40 or older. Diabetes Res. Clin. Pract. 77, 485-488 (2007).

17. Katon, J. G., Reiber, G. E. \& Nelson, K. M. Peripheral neuropathy defined by monofilament insensitivity and diabetes status: NHANES 1999-2004. Diabetes Care 36, 1604-1606 (2013).

18. American Diabetes Association. 11. Microvascular complications and foot care: Standards of Medical Care in Diabetes-2019. Diabetes Care 42, S124-S138 (2019).

19. Boulton, A. J. et al. Comprehensive foot examination and risk assessment: A report of the task force of the foot care interest group of the American Diabetes Association, with endorsement by the American Association of Clinical Endocrinologists. Diabetes Care 31, 1679-1685 (2008).

20. Armstrong, D. G., Lavery, L. A., Vela, S. A., Quebedeaux, T. L. \& Fleischli, J. G. Choosing a practical screening instrument to identify patients at risk for diabetic foot ulceration. Arch. Intern. Med. 158, 289-292 (1998).

21. Services CfMM. Decision Memo for Diabetic Peripheral Neuropathy with Loss of Protective Sensation (LOPS) (CAG-00059N) (2001). 
22. Cabezas-Cerrato, J. The prevalence of clinical diabetic polyneuropathy in Spain: A study in primary care and hospital clinic groups. Neuropathy Spanish Study Group of the Spanish Diabetes Society (SDS). Diabetologia 41, 1263-1269 (1998).

23. Tesfaye, S. et al. Vascular risk factors and diabetic neuropathy. N. Engl. J. Med. 352, 341-350 (2005).

24. Wiggin, T. D. et al. Elevated triglycerides correlate with progression of diabetic neuropathy. Diabetes 58, 1634-1640 (2009).

25. Unmar, Y., Zafar, M. I. \& Gao, F. Factors associated with peripheral neuropathy in type 2 diabetes: Subclinical versus confirmed neuropathy. J. Huazhong Univ. Sci. Technol. Med. Sci. 37, 337-342 (2017).

26. Olaiya, M. T. et al. Use of graded Semmes Weinstein monofilament testing for ascertaining peripheral neuropathy in people with and without diabetes. Diabetes Res. Clin. Pract. 151, 1-10 (2019).

27. Clair, C., Cohen, M. J., Eichler, F., Selby, K. J. \& Rigotti, N. A. The effect of cigarette smoking on diabetic peripheral neuropathy: A systematic review and meta-analysis. J. Gen. Intern. Med. 30, 1193-1203 (2015).

28. Gerrits, E. G. et al. Skin autofluorescence: A tool to identify type 2 diabetic patients at risk for developing microvascular complications. Diabetes Care 31, 517-521 (2008).

29. Adler, A. I. et al. Risk factors for diabetic peripheral sensory neuropathy. Results of the Seattle Prospective Diabetic Foot Study. Diabetes Care 20, 1162-1167 (1997).

30. Karki, D. B. et al. Prevalence of sensory neuropathy in type 2 diabetes mellitus and its correlation with duration of disease. Kathmandu Univ. Med. J. (KUMJ) 14, 120-124 (2016).

31. Debette, S. et al. Midlife vascular risk factor exposure accelerates structural brain aging and cognitive decline. Neurology 77, 461-468 (2011).

32. Power, M. C. et al. Midlife and late-life vascular risk factors and white matter microstructural integrity: The atherosclerosis risk in communities neurocognitive study. J. Am. Heart Assoc. https://doi.org/10.1161/JAHA.117.005608 (2017).

33. Gottesman, R. F. et al. Associations between midlife vascular risk factors and 25-year incident dementia in the Atherosclerosis Risk in Communities (ARIC) cohort. JAMA Neurol. 74, 1246-1254 (2017).

34. Conner, S. C. et al. Mid-life and late-life vascular risk factor burden and neuropathology in old age. Ann. Clin. Transl. Neurol. 6, 2403-2412 (2019).

35. Armstrong, N. M., Bangen, K. J., Au, R. \& Gross, A. L. Associations between midlife (but not late-life) elevated coronary heart disease risk and lower cognitive performance: Results from the Framingham offspring study. Am. J. Epidemiol. 188, 2175-2187 (2019).

36. Hicks, C. W. et al. Associations of cardiac, kidney, and diabetes biomarkers with peripheral neuropathy among older adults in the Atherosclerosis Risk in Communities (ARIC) study. Clin. Chem. 66, 686-696 (2020).

37. Feldman, E. L., Nave, K. A., Jensen, T. S. \& Bennett, D. L. H. New horizons in diabetic neuropathy: Mechanisms, bioenergetics, and pain. Neuron 93, 1296-1313 (2017).

38. Martyn, C. N. \& Hughes, R. A. Epidemiology of peripheral neuropathy. J. Neurol. Neurosurg. Psychiatry 62, 310-318 (1997).

39. Lunn, M. P. Neuropathies and paraproteins. Curr. Opin. Neurol. 32, 658-665 (2019).

40. Koike, H. \& Sobue, G. Paraneoplastic neuropathy. Handb. Clin. Neurol. 115, 713-726 (2013).

41. Chopra, K. \& Tiwari, V. Alcoholic neuropathy: Possible mechanisms and future treatment possibilities. Br. J. Clin. Pharmacol. 73, 348-362 (2012).

42. Gepner, Y. et al. Effects of initiating moderate alcohol intake on cardiometabolic risk in adults with type 2 diabetes: A 2-year randomized, controlled trial. Ann. Intern. Med. 163, 569-579 (2015).

43. Brown, S. J., Handsaker, J. C., Bowling, F. L., Boulton, A. J. \& Reeves, N. D. Diabetic peripheral neuropathy compromises balance during daily activities. Diabetes Care 38, 1116-1122 (2015).

44. Schwartz, A. V. et al. Diabetes-related complications, glycemic control, and falls in older adults. Diabetes Care 31, 391-396 (2008).

45. Timar, B. et al. The impact of diabetic neuropathy on balance and on the risk of falls in patients with type 2 diabetes mellitus: A cross-sectional study. PLoS One 11, e0154654 (2016).

46. Margolis, D. J. \& Jeffcoate, W. Epidemiology of foot ulceration and amputation: Can global variation be explained?. Med. Clin. North Am. 97, 791-805 (2013).

47. Herman, W. H. et al. Use of the Michigan Neuropathy Screening Instrument as a measure of distal symmetrical peripheral neuropathy in Type 1 diabetes: Results from the Diabetes Control and Complications Trial/Epidemiology of Diabetes Interventions and Complications. Diabetes Med. 29, 937-944 (2012).

48. Feldman, E. L. et al. A practical two-step quantitative clinical and electrophysiological assessment for the diagnosis and staging of diabetic neuropathy. Diabetes Care 17, 1281-1289 (1994).

\section{Acknowledgements}

The authors thank the staff and participants of the ARIC study for their important contributions.

\section{Author contributions}

C.W.H. designed and conceptualized study, analyzed the data, interpreted the data, and drafted the manuscript for intellectual content. D.W. analyzed the data, interpreted the data, and drafted the manuscript for intellectual content. B.G.W. interpreted the data and revised the manuscript for intellectual content. K.M. interpreted the data and revised the manuscript for intellectual content. E.S. designed and conceptualized study, analyzed the data, interpreted the data, and revised the manuscript for intellectual content.

\section{Funding}

The Atherosclerosis Risk in Communities study has been funded in whole or in part with Federal funds from the National Heart, Lung, and Blood Institute, National Institutes of Health, Department of Health and Human Services, under Contract No. (HHSN268201700001I, HHSN268201700002I, HHSN268201700003I, HHSN268201700005I, HHSN268201700004I). Dr. Hicks was supported by National Institute of Diabetes and Digestive and Kidney Diseases grant K23DK124515. Dr. Selvin was supported by National Institute of Diabetes and Digestive and Kidney Diseases grants K24DK106414 and R01DK089174. Dr. Matsushita was supported by National Heart, Lung, and Blood Institute grant R21HL133694.

\section{Competing interests}

The authors declare no competing interests.

\section{Additional information}

Supplementary Information The online version contains supplementary material available at https://doi.org/ 10.1038/s41598-021-98565-w. 
Correspondence and requests for materials should be addressed to E.S.

Reprints and permissions information is available at www.nature.com/reprints.

Publisher's note Springer Nature remains neutral with regard to jurisdictional claims in published maps and institutional affiliations.

(c) (i) Open Access This article is licensed under a Creative Commons Attribution 4.0 International cc) License, which permits use, sharing, adaptation, distribution and reproduction in any medium or format, as long as you give appropriate credit to the original author(s) and the source, provide a link to the Creative Commons licence, and indicate if changes were made. The images or other third party material in this article are included in the article's Creative Commons licence, unless indicated otherwise in a credit line to the material. If material is not included in the article's Creative Commons licence and your intended use is not permitted by statutory regulation or exceeds the permitted use, you will need to obtain permission directly from the copyright holder. To view a copy of this licence, visit http://creativecommons.org/licenses/by/4.0/.

(C) The Author(s) 2021 